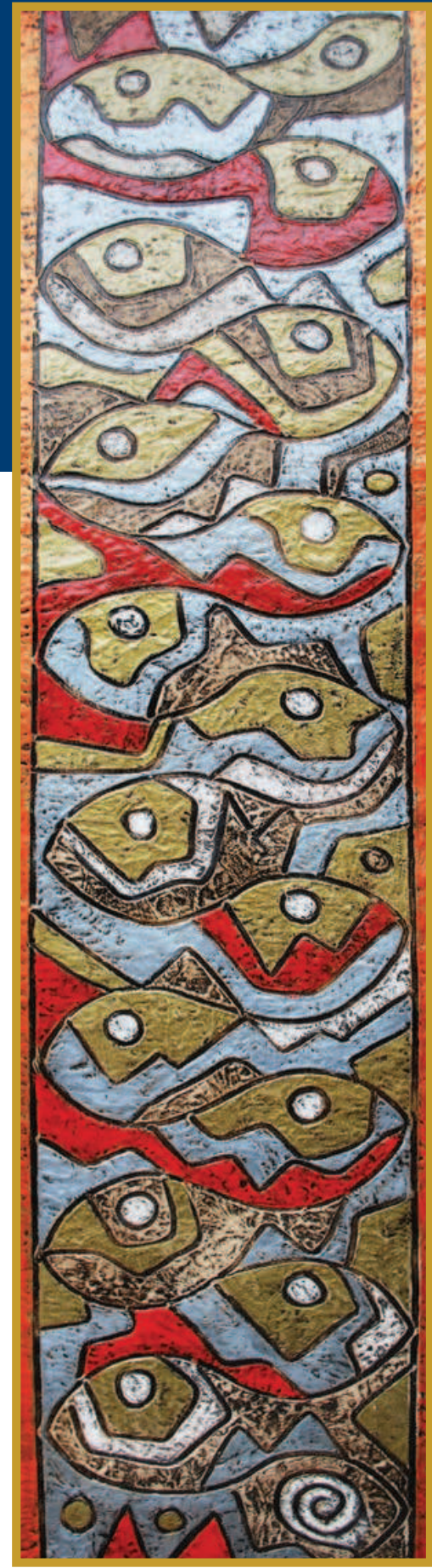

Aychawaykuna (Pescadores) Mixta 2010

\section{Claves de la} espiritualidad en el Documento de Aparecida

Camilo Maccise, ocd*

Al dirigir una mirada hacia la realidad de América Latina y El Caribe, el Documento de Aparecida constata que existe, "como reacción al materialismo, una búsqueda de 'espiritualidad, de oración y de mística' que expresa el hambre y sed de Dios" (DA n. 99, g). Sabemos que no puede existir un trabajo evangelizador que no tenga como punto de partida una experiencia de Dios, una aceptación vital del mensaje de Jesucristo y una apertura a la acción del Espíritu, es decir, una espiritualidad. No se trata de transmitir una doctrina o una serie de enseñanzas sino de una experiencia profunda de la Buena Nueva. Por eso están siempre unidas la espiritualidad, la pastoral y la teología. El Documento de Aparecida propone, directa o indirectamente, una espiritualidad como compromiso con el seguimiento de Jesús y fuente de acción misionera. De manera especial dedica un apartado del capítulo sexto que explica el itinerario formativo de los discípulos misioneros y lo titula "Una espiritualidad trinitaria del encuentro con Jesucristo" (nn. 240-275). Además, en otros muchos lugares se alude a la espiritualidad como origen y meta de la acción evangelizadora. Tener todo esto presente es fundamental para comprender la doctrina y las orientaciones espirituales del

\footnotetext{
Teólogo mexicano, Publicado en "Amerindiaenlared", 21-07-2008 Publicado en VR, n.1, Enero 2008, MadridEspaña.
} 
Documento de Aparecida. Encontramos en éste expresados todos los elementos de la espiritualidad cristiana:

1. El 'aspecto trinitario': experiencia de Dios, seguimiento de Jesucristo, apertura al Espíritu.

2. El 'aspecto teologal': la fe, la esperanza y el amor.

3. Otros elementos fundamentales: la liturgia, la oración, la ascesis, la devoción mariana, la dimensión apostólica.

\section{Una espiritualidad trinitaria}

El capítulo sexto, que trata sobre el 'itinerario formativo de los discípulos misioneros', aborda el tema de una espiritualidad trinitaria, del encuentro con Jesucristo, y afirma que: "una auténtica propuesta de encuentro con Jesucristo debe establecerse sobre el sólido fundamento de la Trinidad-Amor. La experiencia de un Dios uno y trino, que es unidad y comunión inseparable, nos permi te superar el egoísmo para encontrarnos en el servicio al otro. La experiencia bautismal es el punto de inicio de toda espiritualidad cristiana que se funda en la Trinidad" (ibíd., n. 240).

\section{La experiencia de Dios}

El Documento de Aparecida pone de relieve la necesidad que siente el pueblo de Dios de presbíteros-discípulos, que tengan una profunda experiencia de Dios (cfr. ibíd., n. 199) y, hablando de la dimensión espiritual en la formación del cristiano, afirma que ésta debe fundarse en "la experiencia de Dios, manifestado en Jesús, y que lo conduce por el Espíritu a través de los senderos de una maduración profunda" (ibíd., n. 280b). Se trata de la experiencia de Dios Padre "quien nos atrae por medio de la entrega euca- rística de su Hijo (cfr. Jn 6,44), don de amor con el que salió al encuentro de sus hijos, para que, renovados por la fuerza del Espíritu, lo podamos llamar Padre" (DA n. 241).

A este Dios lo experimentamos en la creación, que nos lleva a alabarlo en la belleza y la fecundidad de las tierras latinoamericanas y de El Caribe. También se lo advierte en las 'personas, familias, pueblos y culturas del Continente' (ibíd., n. 6), de manera especial, en el rostro de los pobres en cuya opción preferencial "está implícita la fe cristológica en aquel Dios que se ha hecho pobre por nosotros, para enriquecernos con su pobreza (ibíd., n. 392). Junto a estas experiencias de Dios en la creación y en las personas, se experimenta a Dios en la historia, acompañando los esfuerzos por instaurar su Reino (cfr. DA n. 366, 383).

\section{El seguimiento de Jesucristo}

A pesar de que, como bien señala José Comblin, la parte más débil del Documento es la Cristología, por no tener en cuenta toda la dimensión histórica de la vida de Jesús y de sus enseñanzas, no faltan reflexiones atinadas sobre lo qué es y lo qué significa su seguimiento. Incluso existe alguna referencia implícita a la reflexión cristológica latinoamericana, como cuando se afirma que "una auténtica evangelización de nuestros pueblos implica asumir plenamente la radicalidad del amor cristiano, que se concreta en el seguimiento de Cristo en la cruz; en el padecer por Cristo a causa de la justicia; en el perdón y amor a los enemigos" (ibíd., n. 543). Otro de los textos habla explícitamente de cómo, en el seguimiento de Jesús, "aprendemos y practicamos las bienaventuranzas del Reino, el estilo de vida del mismo Jesucristo: su amor y obediencia filial al Padre, su compasión entrañable ante el dolor humano, su cercanía a los pobres y a los pequeños, su fidelidad a la misión encomendada, su amor servicial hasta el don de 

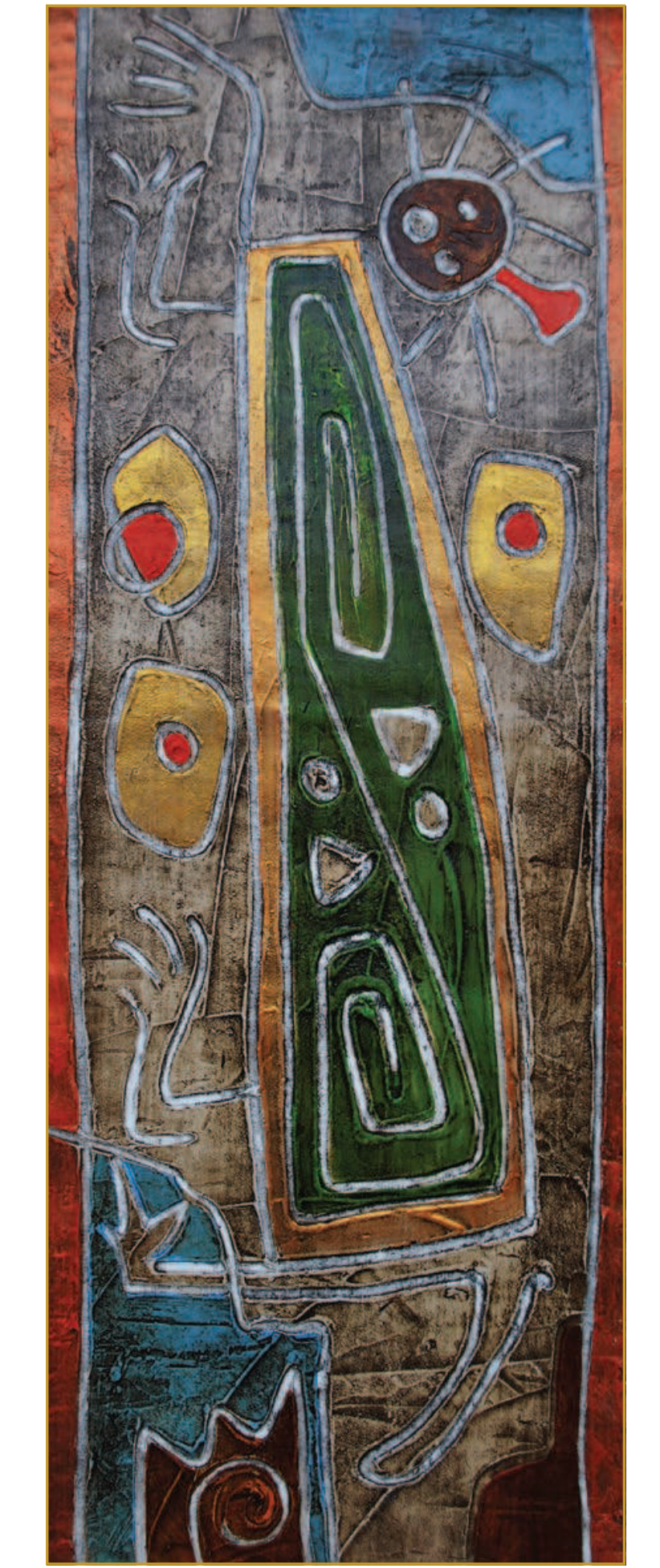

Punchana (Guatuza)

Mixta 2010 su vida. Hoy contemplamos a Jesucristo tal como nos lo transmiten los evangelios para conocer lo que Él hizo por nosotros y para invitarnos a discernir qué es lo que nosotros debemos hacer hoy" (ibíd., n. 139).

El seguimiento de la vida de Jesús implica renovar en nuestra vida la experiencia del ejercicio de su vida, de su humanidad, trabajar por quiénes Él trabajó y vivir lo que el vivió. Jesús experimentó a Dios como Padre, al prójimo como hermanos/as y al mundo como el lugar de encuentro con Dios y el prójimo. Jesús trabajó por la liberación integral del ser humano y padeció a causa de su testimonio de vida persecución, injusticia y muerte.

En esa línea del seguimiento de la historia de Jesús desde nuestra historia, Aparecida señala, que ante una vida sin sentido, es Él quien nos revela el rostro de Dios y nos invita a la comunión con la Trinidad (cfr. ibíd., n. 109). Ante la desesperanza de un mundo sin Dios, que sólo ve en la muerte el término definitivo de la existencia, nos ofrece la resurrección frente a la idolatría de los bienes terrenales; Jesús presenta la vida en Dios como el valor supremo y nos invita a seguirlo (cfr. ibíd., n. 109). Frente al subjetivismo hedonista, Jesús propone entregar la vida para ganarla (cfr. ibíd., n. 110); "ante la exclusión, Jesús defiende los derechos de los débiles y la vida digna de todo ser humano" (ibíd., n.112). No falta tampoco en la doctrina del Documento de Aparecida la implicación ecológica en el seguimiento de Jesús: "ante la naturaleza amenazada, Jesús, que conocía el cuidado del Padre por las criaturas que Él alimenta y embellece (cfr. Lc $12,28)$ nos convoca a cuidar la tierra para que brinde abrigo y sustento a todos los hombres" (DA n. 113).

Vivir la espiritualidad del seguimiento de Jesús a la luz del Documento de Aparecida exige entrar en la dinámica del Buen Samaritano para acercarnos a los que sufren; para generar una sociedad sin excluidos acogiendo a los pequeños y a los pobres y buscando la liberación integral de todos (cfr. ibíd., n.135). 


\section{Apertura al Espíritu}

La vida cristiana es una vida 'según el Espíritu'. En Aparecida encontramos en muchas de sus páginas una doctrina orientadora sobre la presencia y la acción del Espíritu en la Iglesia y en cada uno de sus miembros. Lo presenta como "Espíritu vivificador, alma y vida de la Iglesia... que ha sido derramado en nuestros corazones, gime e intercede por nosotros y nos fortalece con sus dones en nuestro camino de discípulos y misioneros" (ibíd., n.23).

El Documento de Aparecida nos recuerda que el Espíritu nos habla a través de los 'signos de los tiempos' y que "nos identifica con JesúsCamino, abriéndonos a su misterio de salvación para que seamos hijos suyos y hermanos unos de otros; nos identifica con Jesús-Verdad, enseñándonos a renunciar a nuestras mentiras y propias ambiciones, y nos identifica con Jesús-Vida, permitiéndonos abrazar su plan de amor y entregarnos para que otros tengan vida en Él" (ibíd., n.137). Como seguidores de Jesús debemos dejarnos guiar por el Espíritu y "hacer propia la pasión por el Padre y el Reino: anunciar la Buena Nueva a los pobres, curar a los enfermos, consolar a los tristes, liberar a los cautivos y anunciar a todos el año de gracia del Señor (cfr. Lc 4,18-19)" (ibíd., n.152).

El primer fruto de la presencia y de la acción del Espíritu es la comunión entre los discípulos y misioneros. Por eso somos invitados por Jesús y ayudados para vivir en comunión a partir de su presencia en nosotros y en la comunidad de los creyentes en Cristo (cfr. ibíd., n.155). El Espíritu nos envía a la tarea misionera (cfr. ibíd., n.171). El Espíritu nos renueva continuamente y nos da posibilidad de dirigirnos a Dios como Padre, nos ayuda a comprender la Escritura, fortalece nuestra identidad de discípulos y despierta en nosotros la voluntad de anunciar con audacia a los demás lo que hemos escuchado y vivido (cfr. ibíd., n.251).

El Espíritu Santo es invocado para "poder dar un testimonio de proximidad que entraña cercanía afectuosa, escucha, humildad, solidaridad, compasión, diálogo, reconciliación, compromiso con la justicia social y capacidad de compartir, como Jesús lo hizo" (ibíd., n.363). Se nos pide fidelidad al Espíritu Santo que nos conduce a la renovación eclesial, "que implica reformas espirituales, pastorales y también institucionales" (ibíd., n.367).

Hay que aprender a sentir la presencia del Espíritu Santo en los valores del Reino de Dios, en las culturas, para potenciarlas y purificarlas; en los esfuerzos de las personas de buena voluntad; en personas y comunidades que testimonian el evangelio (cfr. ibíd., n. 374). Con la fuerza del Espíritu hay que enfrentar los desafíos del momento actual (cfr. ibíd., n. 551). 


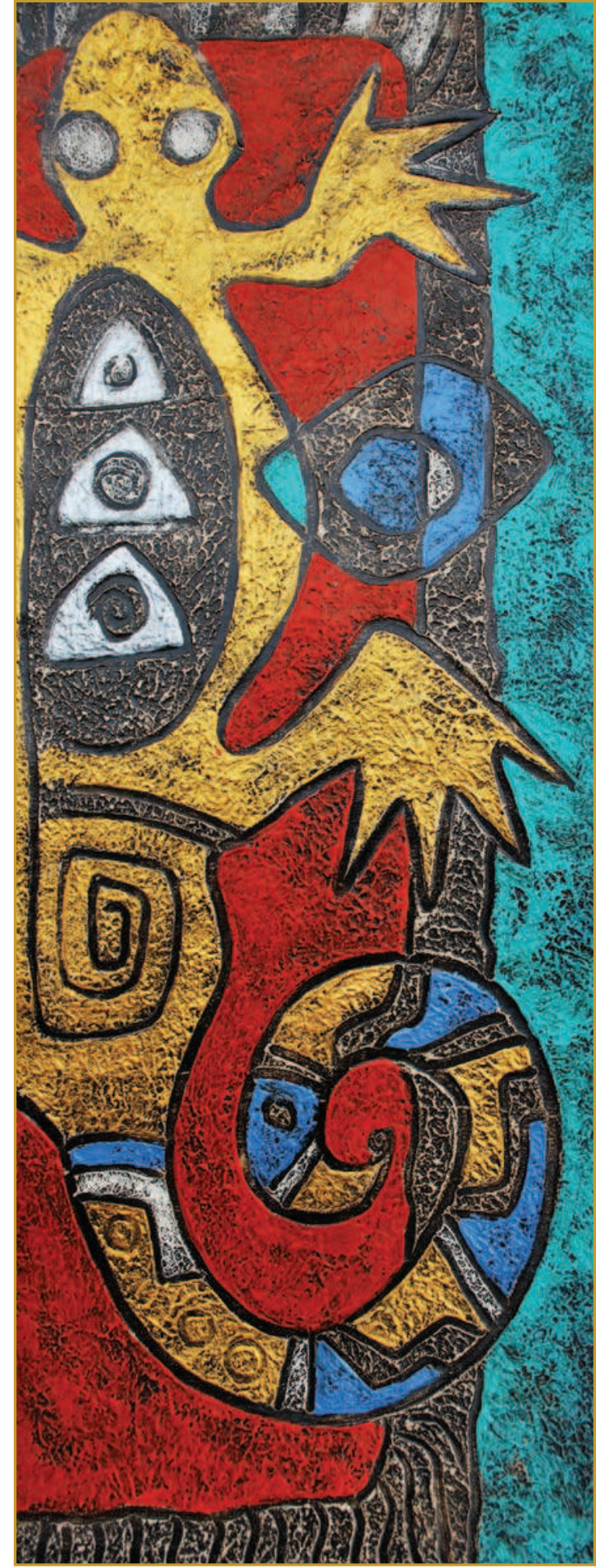

Waksa (Lagarto sabio) Mixta 2010

\section{La fe}

La fe bíblica tiene el sentido de apertura a una persona con confianza y seguridad plenas. Creer en la Escritura es apoyarse en algo sólido y estable; es apoyarse en Dios. La fe es un abrirse al Dios vivo y verdadero, al Dios de la alianza, fiel a sus promesas. A la luz de esta fe se hace la experiencia de Dios, no fuera de la realidad sino dentro de ella: realidad histórica llena de contradicciones y de búsqueda; realidad política, social y económica. La fe en su dimensión social lleva a analizar la realidad a la luz del plan de Dios sobre la humanidad, a anunciar este proyecto divino, a denunciar todo lo que se opone a él. Esta fe conduce a discernir las interpelaciones de Dios en los signos de los tiempos y a descubrir las situaciones de pecado social. Conduce igualmente al compromiso por superar todo lo que contradice la condición de hijos de Dios y de hermanos que Cristo ha establecido entre los seres humanos.

El regreso al concepto bíblico de fe ha hecho que no se la reduzca -como sucedía anteriormente- al hecho de creer verdades. Hoy es entendida como apertura confiada en Dios y disponibilidad para seguir sus caminos; como visión contemplativa que descubre a Dios presente en la realidad y que se expresa en el compromiso del amor hacia los hermanos/as. Aparecida confiesa desde el principio del documento que desea dar "un nuevo impulso a la evangelización, a fin de que estos pueblos sigan creciendo y madurando en su fe" (ibíd., n.16).

Otro de los puntos importantes trata acerca del significado de una fe encarnada en la realidad cuando al describir el método: ver, juzgar y actuar, se manifiesta que esto implica "contemplar a Dios con los ojos de la fe, a través de su Palabra revelada y el contacto vivificante de los sacramentos, a fin de que en la vida cotidiana veamos la realidad que nos circunda a la luz de su providencia, la juzguemos según Jesucristo, Camino, Verdad y Vida, y actuemos desde la Iglesia, Cuerpo místico de Cristo y sacramento universal de salvación, en la propagación del reino de Dios, que se siembra en 
esta tierra y que fructifica plenamente en el cielo" (ibíd., n.19). La fe nos enseña también que "Dios vive en la ciudad, en medio de sus alegrías, anhelos y esperanzas, como también en sus dolores y sufrimientos. Las sombras que marcan lo cotidiano de las ciudades, como por ejemplo, violencia, pobreza, individualismo y exclusión, no pueden impedirnos que busquemos y contemplemos al Dios de la vida también en los ambientes urbanos" (ibíd., n. 513).

Aparecida reconoce como 'testigos de la fe' a muchos de sus miembros quienes fueron perseguidos y asesinados por su empeño a favor de los más pobres y su lucha por la dignidad de cada ser humano (cfr. ibíd., n.98). La fe debe ser vivida con la alegría que lleva a "proclamar el Evangelio de Jesucristo y, en Él, la buena nueva de la dignidad humana, de la vida, de la familia, del trabajo, de la ciencia y de la solidaridad con la creación" (ibíd., n. 103). "La fe nos libera del aislamiento porque nos lleva a la comunión" (cfr. ibíd., n. 156). Jesús se hace presente en una comunidad viva en la fe y el amor fraterno (cfr. ibíd., n. 256). Hay que vivir la fe en la centralidad del misterio pascual de Cristo a través de la eucaristía (cfr. ibíd., n. 251). La religiosidad popular expresa también la fe "porque refleja una sed de Dios, que solamente los pobres y sencillos pueden conocer" (ibíd., n. 258).

La fe debe in-culturarse porque solamente cuando penetra en el sustrato cultural de un pueblo puede ser profesada adecuadamente, entendida y vivida (cfr. ibíd., n. 477). La fe en Dios es compatible con la ciencia $y$, por tanto, hay que valorar los espacios de diálogo entre ambas (cfr. ibíd., n. 495). Ante los desafíos de la nueva evangelización se hace más urgente que nunca "una coherencia entre fe y vida en el ámbito político, económico y social" (cfr. ibíd., n. 505).

\section{La esperanza}

La esperanza cristiana no puede reducirse a la simple espera paciente y resignada de la irrup- ción de lo definitivo en nuestra historia humana. El concepto bíblico de esperanza ilumina la tensión entre lo presente y lo futuro, que será lo definitivo. La redención de Cristo, realizada ya, tiene al mismo tiempo una faceta futura que es objeto de esperanza: la redención se consumará con la resurrección. A la luz del Nuevo Testamento, la esperanza cristiana está hecha de fe, paciencia perseverante y acción (cfr. Rom 5, 3-5) y se apoya en la bondad y fidelidad de Dios manifestadas en Cristo, del cual nada ni nadie nos puede separar (Rom 8, 38-39), y en la presencia del Espíritu (Rom 8,11-23). La esperanza cristiana arrastra también consigo al universo (Rom 8,19-22).

La dimensión activa de la esperanza se orienta al progreso del ser humano y a su liberación y sólo a través de esta al progreso del mundo, de la ciencia y de la técnica. Todo debe estar orientado a la liberación integral de la persona humana. La esperanza de lo definitivo no debe debilitar sino excitar la solicitud para transformar el mundo y la sociedad, porque eso interesa al reino de Dios, ya misteriosamente presente en la tierra (cfr. Gaudium et Spes, 39). La esperanza en su dimensión social lleva a descubrir contemplativamente las semillas de vida y de resurrección en las cosas de cada día, en las situaciones, en las personas, en uno mismo. También la experiencia de la propia pobreza, de las propias limitaciones y de la lentitud de los cambios exige el ejercicio de una esperanza activa, que vive la tensión de la paciencia perseverante.

El Documento de Aparecida presenta la esperanza cristiana desde una doble perspectiva: por una parte descubre los signos de esperanza; y, por otra, la coloca en la línea del Vaticano II que la asocia al compromiso de trabajar por el proyecto de Dios, que comienza en este mundo y que se consumará cuando lleguen los cielos nuevos y la tierra nueva. Se constata que junto con la fe existe en muchos bautizados una esperanza contra toda esperanza que produce la alegría de vivir aún en condiciones muy difíciles (cfr. DA n. 7), porque encuentra a Jesús como roca, paz y vida (cfr. ibíd., n. 21). 


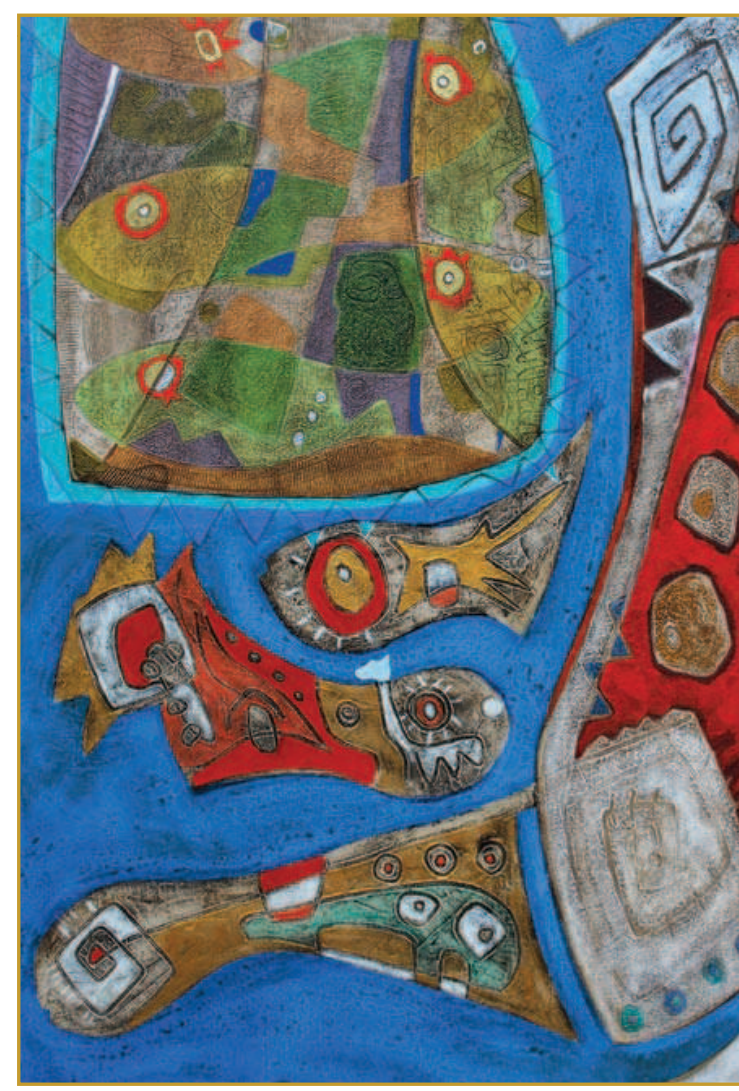

Iñu (Punto de inicio)

Mixta 2010

Entre los signos de esperanza que animan la espiritualidad en América Latina y El Caribe está la caridad de tantas personas anónimas en medio de las injusticias y adversidades. Su testimonio manifiesta la cercanía del poder salvador y liberador del reino de Dios "que nos acompaña en la tribulación y que alienta incesantemente nuestra esperanza en medio de todas las pruebas" (ibíd., n.30).

En la Iglesia 'casa y escuela de comunión' los discípulos comparten la misma fe, esperanza y amor al servicio de la misión evangelizadora (cfr. ibíd., n.158) para iluminar e infundir aliento e inspirar soluciones adecuadas a los problemas de la existencia (cfr. ibíd., n.333). "En el corazón y la vida de nuestros pueblos late un fuerte sentido de esperanza, no obstante, las condiciones de vida que parecen ofuscar toda esperanza. Ella se experimenta y alimenta en el presente, gracias a los dones y signos de vida nueva que se comparte; compromete en la construcción de un futuro de mayor dignidad y justicia y ansía los 'cielos nuevos y la tierra nueva' que Dios nos ha prometido en su morada
Lecturas clave de Aparecida

eterna" (ibíd., n. 536). "Sólo así el Continente de la esperanza puede llegar a tornarse verdaderamente el Continente del amor" (ibíd., n. 543).

\section{El amor}

A la luz de la Biblia, tanto en el Antiguo como en el Nuevo Testamento, se habla de la conexión que existe entre la experiencia de Dios y el amor a los demás. Los profetas expresan de muchas maneras esta experiencia de Dios en el amor al prójimo. Llaman a esto 'conocimiento de Yahvé. En él se manifiesta una relación existencial con Dios que compromete profundamente con el prójimo. 'Conocer a Yahvé' es 'juzgar la causa del humillado y del pobre' (Jer 22, 16). Miqueas resume las consecuencias de la auténtica experiencia de Dios, cuando escribe: "Te he explicado, hombre, el bien, lo que Dios desea de ti: simplemente que respetes el derecho, que ames la misericordia y que andes humilde con tu Dios" (Miq 6, 8). Esto es lo que ellos llaman 'religión interior' o 'religión auténtica'. En la práctica de la justicia, del derecho, de la misericordia el ser humano se encuentra con Dios. Junto con la fe, este es el fundamento de la verdadera religión y espiritualidad. En ella no hay lugar para pseudoexperiencias de Dios en el formalismo y en el ritualismo que pretenden tranquilizar la conciencia. La verdadera experiencia de Dios está hecha de la integración de la fe en Dios con el amor al prójimo (cfr. Jer 9, 22-23).

La misma doctrina aparece en el Nuevo Testamento. De manera particular el evangelista San Juan parte de una profunda experiencia de lo que es la comunión con Dios en la interioridad expresada en la comunión fraterna. Para ver si existe una real apertura al Dios trascendente y manifestado en Cristo basta examinar si se manifiesta en el amor a los demás. Si no, se trata sólo de una experiencia imaginada o vacía de contenido real (cfr. Jn 3, 16; 1 Jn 4, 11-20).

El experimentar a Dios en la interioridad trae también consigo una invitación a cambiar la 


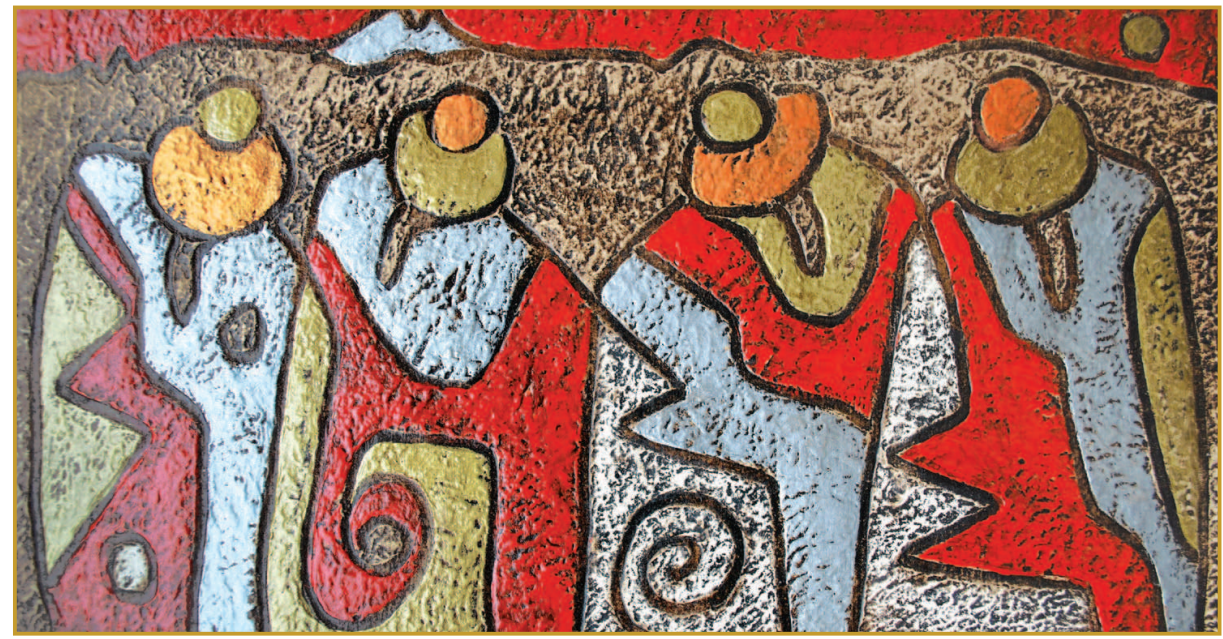

Ayllu (Familia)

historia. Hay que luchar por una sociedad basada en el derecho y la justicia (cfr. Jer 21,11-22, 4). El amor hacia el prójimo posee una dimensión histórica, que se debe concretizar en la acción exigida por las nuevas circunstancias siempre cambiantes. Hoy se requieren nuevas mediaciones, que den al amor cristiano la eficacia que le falta en ocasiones: "exigencias como la noviolencia cristiana, la protección del ambiente, la planificación responsable de la familia, la prevención sanitaria, la responsabilidad política y otras, pueden tener, por lo menos, tanta importancia como los preceptos particulares, que anteriormente eran considerados y predicados como el contenido del amor al prójimo" (Rahner, 1984: 15).

Las mismas obras de misericordia, enumeradas en el texto de Mateo, en el que se describe el juicio final (Mt 25, 31-46), deben ser interpretadas, en la misión evangelizadora, también desde una visión social. Dar de comer y beber al necesitado significa colaborar para que en la sociedad se creen fuentes de trabajo y estructuras que permitan a todos, a través de una retribución digna, satisfacer estas necesidades elementales de la persona humana. Visitar al enfermo, sería trabajar para que nadie carezca de seguridad social y médica. Preocuparse de quién está en la cárcel, debe llevar a la denuncia de la violación de los derechos humanos de los prisioneros, de las torturas que se les infligen, de los arrestos arbitrarios.

El Documento de Aparecida reafirma esta dimensión social del amor al hablar de la opción preferencial por los pobres entre los que menciona comunidades indígenas y afrodescendientes, jóvenes sin oportunidades, desempleados, migrantes, desplazados, campesinos sin tierra, niños y niñas sometidos a la prostitución infantil, millones de personas y de familias que viven en la miseria, quienes dependen de las drogas, las personas con discapacidad, portadores del VIH, enfermos de Sida, víctimas del terrorismo, de conflictos armados y de inseguridad ciudadana (cfr. conferencia de Aparecida, doc. aprobado, n. 65). La imagen de Dios en estas personas que sufren está ofuscada y ultrajada. Dios sufre en ellos e invita a una conversión y a anunciar su sufrimiento para evangelizar a todos, invitándolos a un compromiso de auténtica solidaridad con dimensiones sociales.

Frente a la globalización, Aparecida promueve una globalización diferente "que esté marcada por la justicia y por el respeto a los derechos humanos" (ibíd., n. 68). En el mismo Documento se subraya "la inseparable relación entre amor a Dios y amor al prójimo, que invita a todos a suprimir las graves desigualdades sociales y las enormes diferencias en el acceso a los bienes" (ibíd., n. 358). Al hablar del reino de Dios, la justicia social y la caridad cristiana, Aparecida vuelve a poner de relieve la dimensión social del amor que no puede faltar en una auténtica espiritualidad en América Latina: "el amor de misericordia para con todos los que ven vulnerada su vida en cualquiera de sus dimensiones, como bien nos muestra el Señor en todos sus gestos de misericordia, requiere que 


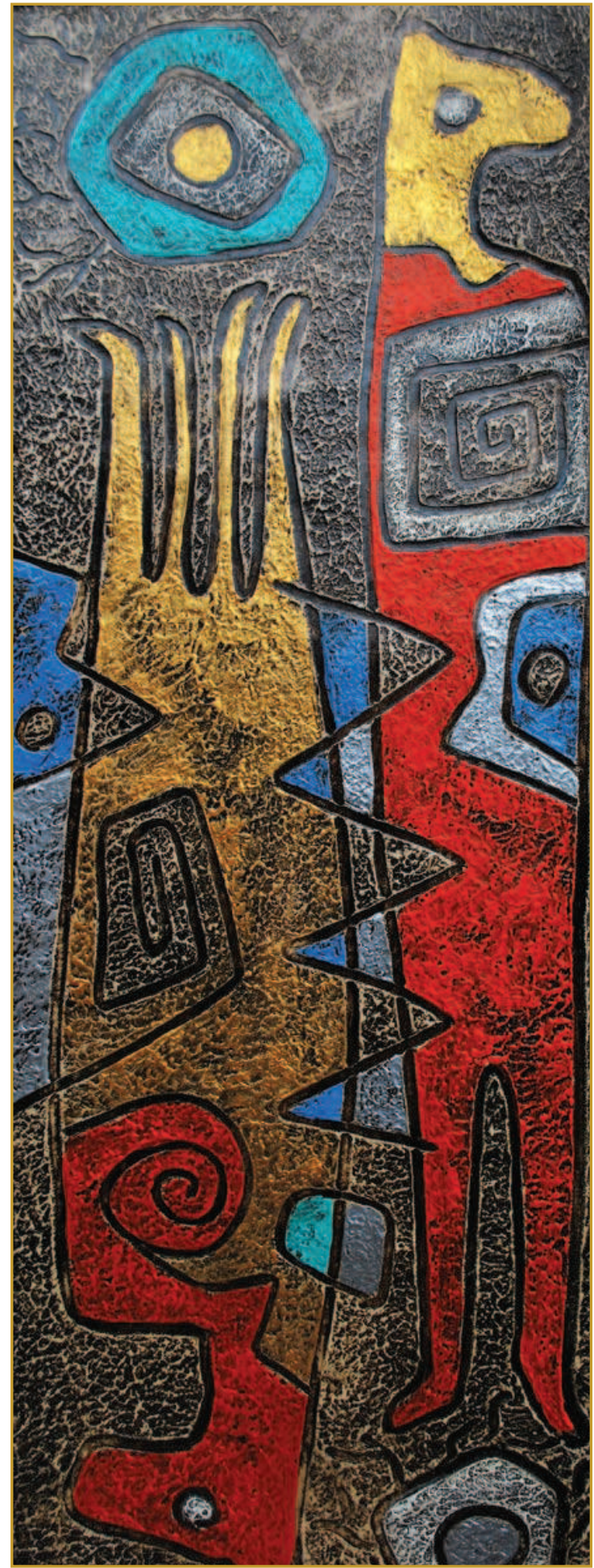

Andi (Andes)

Mixta 2010 socorramos las necesidades urgentes, al mismo tiempo que colaboremos con otros organismos o instituciones para organizar estructuras más justas en los ámbitos nacionales e internacionales. Urge crear estructuras que consoliden un orden social, económico y político en el que no haya inequidad y donde haya posibilidades para todos" (ibíd., n. 384; cfr. 385-386).

Los obispos se comprometen a trabajar para que la Iglesia sea "con mayor ahínco, compañera de camino de nuestros hermanos más pobres, incluso hasta el martirio. Hoy queremos ratificar y potenciar la opción del amor preferencial por los pobres hecha en las Conferencias anteriores. Que sea preferencial implica que debe atravesar todas nuestras estructuras y prioridades pastorales. La Iglesia latinoamericana está llamada a ser sacramento de amor, solidaridad y justicia entre nuestros pueblos" (ibíd., n. 396).

\section{Liturgia y oración}

Elementos importantes en la espiritualidad cristiana son la oración litúrgica y personal. La renovación litúrgica del Vaticano II hizo cambiar el concepto y la experiencia de la liturgia. Durante varios siglos ésta fue considerada como una serie de ritos que había que cumplir o como una representación religiosa solemne. Colocada al margen de la vida influía poco en ella. Actualmente se la considera especialmente como la palabra de Dios celebrada en la esperan$\mathrm{za}$, después de haberla acogido por la fe y con el compromiso de vivir sus exigencias en el amor. Existe un dinamismo de continuidad entre liturgia y vida. La presencia de Cristo y del Espíritu en las celebraciones se percibe exigente para el 'después' de la liturgia.

El Documento de Aparecida afirma que "la renovación litúrgica acentuó la dimensión celebrativa festiva de la fe cristiana, centrada en el misterio pascual de Cristo Salvador, en particular en la Eucaristía... Se han hecho algunos esfuerzos por in-culturar la liturgia en los pue- 
blos indígenas y afroamericanos" (ibíd., n. 99b). $\mathrm{Al}$ hablar del encuentro con Jesucristo recuerda que se da de modo admirable en la liturgia. Al vivirla se penetra en los misterios del Reino y los discípulos misioneros expresan de modo sacramental su vocación, se comprometen en el seguimiento de Cristo, en la acción misionera y en la vida de nuestros pueblos en Él (cfr. ibíd., n. 250). También se da un encuentro con Jesucristo en los otros sacramentos. En el de la reconciliación se experimenta el perdón misericordioso de Dios y se tiene la liberación de cuanto impide permanecer en su amor (cfr. ibíd., n. 254).

La experiencia bíblica de Dios traza el camino de toda auténtica experiencia que fundamente la vida de oración. En la Escritura, la experiencia de Dios se tiene en la vida; en la búsqueda de la autenticidad humana; en los acontecimientos de la historia leídos en clave de fe. Esta experiencia compromete además con la vida especialmente en las relaciones con los demás. El amor al prójimo es, al mismo tiempo, camino para la experiencia de Dios y expresión de su autenticidad. De allí se deriva un impulso para transformar la historia colaborando con Dios en el advenimiento de su Reino. Aparecida reafirma todo esto y hace ver que la oración personal y comunitaria "es el lugar donde el discípulo, alimentado por la Palabra y la Eucaristía, cultiva una relación de profunda amistad con Jesucristo y procura asumir la voluntad del Padre. La oración diaria es un signo del primado de la gracia en el itinerario del discípulo misionero" (ibíd., n. 255). La oración se nutre del contacto con la palabra de Dios en la Escritura. Ella es fuente de vida y alma de la acción evangelizadora (cfr. ibíd., n. 247). De manera particular se recomienda la lectio divina (cfr. ibíd., n. 249).

\section{La ascesis}

La ascesis, entendida como abnegación evangélica, es un elemento necesario en la espiritualidad cristiana. Es un modo de participar en el misterio de la muerte y resurrección de Cristo. En Aparecida, la exigencia de la abnegación evangélica aparece cuando se habla del seguimiento de Jesús, su sentido y sus consecuencias (cfr. ibíd., n. 129-142). La ascesis se vive como parte de ese seguimiento y propicia el crecimiento en la fe, la esperanza y el amor. Se trata de una abnegación evangélica en conexión con la vida y que se expresa en las renuncias que implica el anuncio del reino. Ese trabajo exige renuncias y vencimientos continuos. Por otro lado, está abierto a la incomprensión y persecución que ponen a prueba la esperanza activa.

Bajo esta línea se inicia la tarea de emprender con un respeto por la ecología como dimensión social de la misma. Se trata de evitar una explotación de la naturaleza para enriquecimiento y poderío sin interesarse por otros grupos humanos de hoy y de mañana, sometiendo la creación con una orientación antropocéntrica y con proyección social. Con esa ascesis ecológica se trata de abrir camino a una espiritualidad que nace de una vida sencilla y sobria y que ponga de relieve la superioridad del ser humano sobre la naturaleza. A un nivel social compromete en el trabajo por la justicia social en las relaciones nacionales e internacionales. Aparecida invita a este tipo de ascesis ecológica cuando, hablando del destino universal de los bienes, dice: "la mejor forma de respetar la naturaleza es promover una ecología humana abierta a la trascendencia que respetando la persona y la familia, los ambientes y las ciudades, sigue la indicación paulina de recapitular todas las cosas en Cristo y de alabar con Él al Padre (cfr. 1 Co 3, 21-23). El Señor ha entregado el mundo para todos, para los de las generaciones presentes y futuras. El destino universal de los bienes exige la solidaridad con la generación presente y con las futuras. Ya que los recursos son cada vez más limitados, su uso debe estar regulado según un principio de justicia distributiva respetando el desarrollo sostenible" (ibíd., n.126). Hablando del cuidado del medio ambiente menciona la necesidad de ejercer responsablemente el dominio humano sobre la tierra y los recursos 
"educando para un estilo de vida de sobriedad y austeridad solidarias" (ibíd., n.474 a).

\section{La dimensión apostólica}

Si la vida cristiana es una vida según el Espíritu, la acción-como dijimos- es parte también de la espiritualidad. Uno de los desafíos que se presentan en cada época de la historia a los creyentes en Jesucristo es el de cómo ser testigos "de la muerte y resurrección de Nuestro Señor Jesucristo, y señal del Dios verdadero" (LG. 38). En otras palabras, cómo anunciar en un lenguaje inteligible la buena noticia de salvación.

El problema no está en el contenido de la evangelización sino en el modo de presentarlo en las circunstancias que, por otra parte son diferentes y van desde las sociedades de abundancia y consumo hasta las de sociedades explotadas donde la injusticia mantiene en condiciones infrahumanas a vastos sectores de la población. Estas situaciones arduas y complejas cuestionan a los cristianos y los invitan a la creatividad, a la audacia pero, sobre todo a la conversión al evangelio. Sólo mirando la misión evangelizadora desde la perspectiva de Cristo y siguiendo su ejemplo en el anuncio del Reino, será posible encontrar nuevos caminos para presentar vivo, actual y dinámico el mensaje liberador del evangelio.

La primera exigencia para la misión evangelizadora es la de la renovación de la vida, espiritualidad misionera que tiene como punto de partida la constatación de "las condiciones de vida de muchos abandonados, excluidos e ignorados en su miseria y su dolor, contradicen el proyecto del Padre e interpelan a los creyentes a un mayor compromiso a favor de la cultura de la vida. El Reino de vida que Cristo vino a traer es incompatible con esas situaciones inhumanas" (DA n. 358).

El compromiso misionero debe llevar asumir con nueva fuerza la opción por los pobres y a trabajar por la promoción humana y la auténtica liberación, que debe ser integral, es decir, debe promover a todos los hombres y a todo el hombre (cfr. ibíd., n. 399). Como punto de partida se requiere una experiencia personal de fe que conduce a la conversión y lleva a vivir la fraternidad y a profundizar el contenido de la revelación 
para poder asumir el compromiso misionero. Se trata de transmitir experiencia más que doctrina. "La conversión pastoral de nuestras comunidades exige que se pase de una pastoral de mera conservación a una pastoral decididamente misionera" (ibíd., n. 370). La espiritualidad de la misión impedirá a los creyentes instalarse en la comodidad y en la tibieza al margen del sufrimiento de los pobres del Continente. "Esperamos un nuevo Pentecostés que nos libre de la fatiga, la desilusión, la acomodación al ambiente; una venida del Espíritu que renueve nuestra alegría y nuestra esperanza. Por eso, se volverá imperioso asegurar cálidos espacios de oración comunitaria que alimenten el fuego de un ardor incontenible y hagan posible un atractivo testimonio de unidad 'para que el mundo crea' (Jn 17,21)” (ibíd., n.362).

\section{María, discípula y misionera}

Vista desde la realidad latinoamericana, María aparece como el rostro materno y misericordioso de Dios: como señal de la presencia y cercanía del Padre y de Cristo. Dos aspectos se descubren en María a la luz del evangelio: su apertura a Dios y su cercanía al pueblo. María es vista como peregrina de la fe y de la esperanza, escuchando la palabra de Dios en la Escritura y en la vida, creyendo en esa palabra y viviendo sus exigencias en todas las circunstancias. En el capítulo sexto: El itinerario formativo de los discípulos misioneros, el Documento de Aparecida presenta a María desde la perspectiva de discípula y misionera. "Del evangelio, emerge su figura de mujer libre y fuerte, conscientemente orientada al verdadero seguimiento de Cristo. Ella ha vivido por entero toda la peregrinación de la fe como madre de Cristo y luego de los discípulos, sin que le fuera ahorrada la incomprensión y la búsqueda constante del proyecto del Padre" (DA n. 266).

María es también "la gran misionera continuadora de la misión de su Hijo y formadora de misioneros. Ella, así como dio a luz al Salvador del mundo, trajo el evangelio a nuestra América"

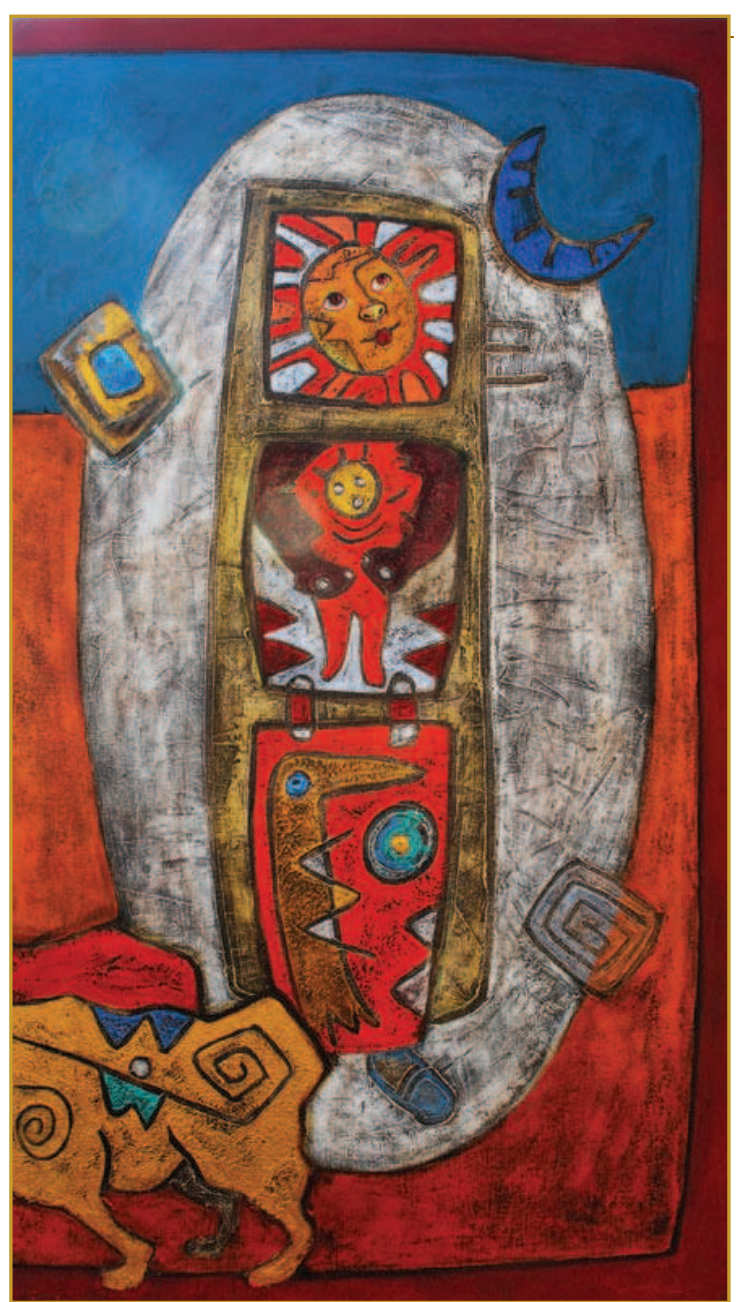

Pachataway (Tejiendo el tiempo, espacio... la vida)

Mixta 2010

(ibíd., n. 269). "María ayuda a mantener vivas las actitudes de atención, de servicio, de entrega y de gratuidad que deben distinguir a los discípulos de su Hijo... Crea comunión y educa a un estilo de vida compartida y solidaria, en fraternidad, en atención y acogida del otro, especialmente si es pobre y necesitado" (ibíd., n.272). "El canto del Magnificat muestra a María como mujer capaz de comprometerse con su realidad y de tener una voz profética ante ella" (ibíd., n. 451).

\section{Bibliografía}

- Documento Conclusivo de Aparecida, 2007, $2 \mathrm{da}$. Edición, 13-31 de mayo 2007. Centro de publicaciones del CELAM, Bogotá: Imprenta San Pablo.

- RAHNER, K. (1984), Chi è tuo fratello, Roma, 15.

- CONFERENCIA DE APARECIDA, Documento aprobado, n.65. 